\title{
Effects of altered gravity induced by clinorotation on the cholinesterase activity of the non-sentient model Paramecium primaurelia (Protozoa)
}

\author{
Francesca Sardi, ${ }^{1}$ Martina Rossi, ${ }^{1}$ Sara Ferrando, ${ }^{2}$ Maria Angela Masini, ${ }^{3}$ Federico Biggi, ${ }^{3}$ \\ Andrea Amaroli ${ }^{1,4}$ \\ ${ }^{1}$ Laboratory of Protistology, Department of Earth Science, Environment and Life, University of Genoa; ${ }^{2}$ Laboratory of \\ New Model Organism (NeMo LAB), Department of Earth, Environmental and Life Sciences, University of Genoa; \\ ${ }^{3}$ Laboratory of Space Biology, Department of Sciences and Technology Innovation, University of Piemonte Orientale; \\ ${ }^{4}$ Department of Surgical Sciences and Integrated Diagnostic, University of Genoa, Italy
}

\begin{abstract}
Compounds known as chemical mediators, including acetylcholine, have been found not only in animals and humans, but also in living organisms, like protozoa, which lack nervous system. In Paramecium primaurelia has been described a cholinergic system, which is proven to play an important role in cell-cell interactions during its developmental cycle. In our work we investigated the effects of exposure to simulated microgravity (3D Random Positioning Machine, $56 \mathrm{rpm}, 10^{-6} \mathrm{~g}$ ) on the cholinesterase activity of the eukaryote unicellular-organism alternative-model $P$. primaurelia. Our results show that the exposure of $P$. primaurelia to microgravity for $6 \mathrm{~h}, 24 \mathrm{~h}, 48 \mathrm{~h}$ affects the localization and the amount of cholinesterase activity compared
\end{abstract}

Correspondence: Andrea Amaroli, Department of Surgical Sciences and Integrated Diagnostic, University of Genoa, Largo R. Benzi 10, 16132 Genoa, Italy.

E-mail: andrea.amaroli.71@gmail.com

Key words: Microgravity; Simulated microgravity;

Acetylcholinesterase; Neurotransmitters; Cholinergic system.

Contributions: AA, MM and SF conceived and designed the experiments. FB, FS and MR performed the experiments and collected data. $\mathrm{AA}, \mathrm{MM}$ and SF performed the data analyses. AA, MM, MR and SF wrote the manuscript.

Conflict of interest: the authors declare no potential conflict of interest.

Funding: none.

Received for publication: 30 August 2017.

Revision received: 15 December 2017.

Accepted for publication: 18 December 2017.

(C) Copyright F. Sardi et al., 2018

Licensee PAGEPress, Italy

Journal of Biological Research 2018; 91:7034

doi:10.4081/jbr.2018.7034

This article is distributed under the terms of the Creative Commons Attribution Noncommercial License (by-nc 4.0) which permits any noncommercial use, distribution, and reproduction in any medium, provided the original author(s) and source are credited. to cells grown under Earth gravity conditions ( $1 \mathrm{~g})$. However, these effects are transient since $P$. primaurelia restores its normal cholinesterase activity after $72 \mathrm{~h}$ under microgravity conditions, as well as cells exposed up to $72 \mathrm{~h}$ to microgravity and then placed under terrestrial gravity for $48 \mathrm{~h}$.

\section{Introduction}

Life on Earth evolved in an environment characterized by chemical-physical properties which gradually changed from the earliest times to the present. These slow and progressive shifts led to the affirmation of organisms able to adapt and to survive in a new environment. Therefore, organisms living on our planet grow and develop under specific environmental conditions in terms of atmosphere, magnetic fields, sun radiation and gravity.

Gravity, in particular, has been a pervasive factor throughout evolutionary history. Actually, also the unicellular eukaryoteorganisms used this external track to find and to stay in favorable living condition, which offers ecological advantages. ${ }^{1}$

In the last decade there was a reborn interest in Space, which raised new questions about the ability of terrestrial organisms to live in an environment different from the original one.

After space flights, for example, astronauts experience neurophysiological problems like alterations in movement/ orientation control ${ }^{2}$ and dysfunctions in kinematics and postural adaptation. $^{3}$

Neurophysiological structure-function correlation studies on Central Nervous System neurons indicate that these are less active in real and simulated microgravity, ${ }^{4}$ by showing possible effects on neurogenesis, neural regeneration and signal transmission. ${ }^{5}$

It is well known that protozoa are a simplified model for functional studies on neurons. In fact, there are numerous similarities between ciliated protozoa and invertebrate and vertebrate nervous cell; ${ }^{1}$ ciliates are able to behave as sensory receptors (like sensory cells), transductive-integrative systems (like nerve cells) and effectors (like muscular cells).

It is not coincidence that cholinergic molecules and nitrergic signal transduction pathway, responsible for neurotransmission in Metazoa, have been identified in Protozoa. ${ }^{6-9}$ In addition, informations derived from both the Paramecium genome sequencing ${ }^{10}$ and the experimental studies on Paramecium ${ }^{11-17}$ have demonstrated that this protozoan is excellent model for studies on humans.

Concerning the space research, attention has been focalized on 
the effect of microgravity on Paramecium. Authors observed that the growth rate of Paramecium tetraurelia increased in microgravity and simulated-microgravity ${ }^{1,18,19}$ as well as Paramecium biaurelia cells swam faster under altered gravity induced by clinorotation. ${ }^{20}$

However Sawai et al. ${ }^{21}$ point out that $P$. tetraurelia reduced proliferation rhythm under slow-clinorotation and in this condition the swimming velocity decreased too.

Lastly, Hemmersbach et al. ${ }^{22}$ showed gravity-dependent decrease in Paramecium cAMP level while cGMP concentration was gravity-independent.

On this basis, in our work we investigated the effect of the exposure to simulated microgravity $\left(10^{-6} \mathrm{~g}\right)$, generated by a $3 \mathrm{D}$ Random Positioning Machine (56 rmp) on the cholinesterase (ChE) activity of the eukaryote unicellular-organism alternative-model Paramecium primaurelia.

\section{Materials and Methods}

\section{Clinostat: characteristics and specifications}

Sawai et al..$^{21}$ reported that the experiment on Paramecium cells performed by slow-clinorotation $(2.5 \mathrm{rpm})$ with the RT-5 TAITEC rotator (Tokyo) was not connected with those under microgravity and simulated microgravity by fast-rotating clinostat. In addition Russomano et al. ${ }^{23}$ showed the high reproducible quality of simulated microgravity generated by $3 \mathrm{D}$ clinostat on cell and to predict the effect of biological specimens prolonged exposure to space. Therefore, for our experimental purpose, we used a 3D special machinery called Random Positioning Machine (RPM) (Dutch Space, Netherland), which has been kept under fastcontinuous rotation at $56 \mathrm{rpm}$, at the temperature of $24^{\circ} \mathrm{C}$, to generate a simulated microgravity of $10^{-6} \mathrm{~g}$.

\section{Paramecium primaurelia and culturing methods}

The cell cultures of $P$. primaurelia were grown at $24^{\circ} \mathrm{C}$ in tubes with lettuce infusion, inoculated with Enterobacter aerogenes as food. ${ }^{14,16}$ The lettuce medium was obtained by drying green leaves from organic farming for $1 \mathrm{~h}$ at $180^{\circ} \mathrm{C}$. Thirty grams of dried leaves were boiled for $15 \mathrm{~min}$ in $1 \mathrm{~L}$ of distilled water. The concentrated infusion thus obtained was filtered and divided into tubes $(10 \mathrm{~mL}$ per tube). The tubes were closed, properly autoclaved at $120^{\circ} \mathrm{C}$ for $20 \mathrm{~min}$ and then stored at $4^{\circ} \mathrm{C}$. The concentrated infusion was diluted into $500 \mathrm{~mL}$ of distilled water, balanced to $\mathrm{pH} 7.1$ and autoclaved $\left(120^{\circ} \mathrm{C}, 20 \mathrm{~min}\right)$ into $50-\mathrm{mL}$ tubes. Logarithmic growing cells of $P$. primaurelia were transferred onto a depression slide. The cells were starved until they reached autogamy, a process involving a nuclear reorganization that resets the age of Paramecium cells.

Autogamy was detected using 4,6-diamidino-2-phenylindole (DAPI), a fluorescent compound that stains the macronucleus in blue. Cell cultures were considered in the autogamy phase when the totality $(100 \%)$ of 30 cellular samples showed the typical fragmented macronucleus. The autogamous cells were isolated onto a depression slide by using a glass micropipette and they were fed with E. aerogenes. It is known that autogamous Paramecium cells have a constant fission rate from 10 to 30 days. As consequence, after 15 days from the autogamy process, the monoclonal cells cultures were used for the experimental purposes, as suggested by Amaroli et al. ${ }^{14,16}$

\section{Experimental samples}

Our studies were carried out on monoclonal cell cultures of $P$. primaurelia transferred into tubes $(5 \mathrm{~mL})$ filled completely with bacterized lettuce medium, in order to avoid the formation of fluxes during the clinorotation. ${ }^{23}$ The tubes were closed and positioned in the 3D RPM under continuous rotation (simulated microgravity, $10^{-6} \mathrm{~g}$ ). Ground controls were placed onto the supporting frame of the same machine, in order to subject all cells to the same vibration. ${ }^{23}$ The experiment was performed at a temperature of $24^{\circ} \mathrm{C}$.

The different samples were named as follows:

Control: sample placed on the non-rotating arm of the clinostat and exposed to the Earth's gravity for 6 h, 24 h, 48 h or $72 \mathrm{~h}$.

Micro $(g)$ : sample exposed to simulated microgravity for $6 \mathrm{~h}$, $24 \mathrm{~h}, 48 \mathrm{~h}$ or $72 \mathrm{~h}$.

Rec: sample exposed to simulated microgravity for $24 \mathrm{~h}, 48 \mathrm{~h}$ or $72 \mathrm{~h}$ and then resubmitted to Earth's gravity for $24 \mathrm{~h}, 48 \mathrm{~h}$ or $72 \mathrm{~h}$.

To detect the ChE activity by cytochemical reaction, cell samples were fixed with $2 \%$ paraformaldehyde in phosphatebuffered saline (PBS) for $120 \mathrm{~min}$ at $24^{\circ} \mathrm{C}$. Cells were then transferred onto slides and allowed to air-dry.

To perform the non-denaturing electrophoresis and the immunoblot analysis, cell samples were collected by centrifugation and lysed by freezing at $-80^{\circ} \mathrm{C}$ for $10 \mathrm{~min}$. Proteins were extracted in $0.1 \%$ Triton $\mathrm{X}-100$ and the total protein concentration was evaluated using the BIO-RAD protein assay kit. ${ }^{17}$

\section{Cytochemical procedure to detect the cholinesterase activity in Paramecium primaurelia}

The presence and localization of the ChE activity was investigated by incubating the Control, $\operatorname{Micro}(g)$ and Rec samples overnight at $4{ }^{\circ} \mathrm{C}$ with the acetyl- $\beta$-methyl thiocholine iodide (AcTChI) substrate according to the Karnovsky and Roots method, ${ }^{24}$ modified by Falugi et al. ${ }^{25}$ Samples were then washed in $0.1 \mathrm{M}$ PBS, pH 7.4. Nuclei were counterstained with DAPI (1:10,000 in PBS for $5 \mathrm{~min}$ ). Cells were observed under a Leica DMRB Epi-fluorescence microscope equipped with four Leica objectives: N Plan $2.5 \times / 0.07$, PL Fluotar $10 \times / 0.30$, PL Fluotar $20 \times / 0.50$, PL Fluotar $40 \times / 0.70$, PL Fluotar $100 \times / 1.3$ Oil. Images were acquired with a Leica CCD camera DFC420C equipped with the Leica Application Suite software, Version 3.7.0 (Leica, Germany). Different images of the same cell, acquired using Normanski imaging and epi-fluorescence, were overlapped by using Adobe Photoshop CS6 Extended. We used the ImageJ 1.33J software (National Institute of Health, Bethesda, MD, USA) to evaluate the ChE activity (optical density) in the experimental cell samples (30 cells for sample).

\section{Non-denaturing electrophoresis to detect the cholinesterase activity in Paramecium primaurelia}

The amount of the ChE activity was investigated by nondenaturing electrophoresis on the Control, $\operatorname{Micro}(g)$ and $\operatorname{Rec}$ samples. ChE-like molecules were separated on a $8 \%$ polyacrylamide running gel. Electrophoresis was carried out at 12 $\mathrm{mA}$, for $16 \mathrm{~h}$ at $5^{\circ} \mathrm{C}$, according to the procedure described by Falugi et al. ${ }^{25}$ The ChE activity was detected with the Karnovsky and Roots method, ${ }^{24}$ using AcTChI as substrate. Electrophorus electricus AChE (Sigma-Aldrich) was used as positive control. The $\beta$-actin was used as loading control and detected by immunoblot analysis with a commercial antibody. ${ }^{17}$ We used the Image J $1.33 \mathrm{~J}$ software (National Institute of Health, Bethesda, MD, USA) to evaluate the optical density (O.D.) of the experimental samples bands. To quantify the enzyme activity, the data were expressed as O.D. of the sample band normalized with the $\beta$-actin. ${ }^{26}$ 


\section{Statistical analysis}

The experiments were carried out at least in triplicate. The significant differences between the controls and the irradiated samples were determined by using one-way ANOVA followed by the Tukey-Kramer multi-comparison test (GraphPad InStat 3).

\section{Results}

No difference in the localization and amount of the ChE activity was observed in control cells. Therefore, the imperceptible vibration was not effective on the parameters here considered, so all the observation on control cells are reported and analyzed together, with no distinction among times.

\section{Effects of simulated microgravity on the localization of the cholinesterase activity in Paramecium primaurelia}

Figure 1 shows the localization of the ChE in cells of $P$. primaurelia exposed to simulated microgravity from $6 \mathrm{~h}$ up to $72 \mathrm{~h}$ and stained with the Karnovsky and Roots method. After $6 \mathrm{~h}$ of exposure to simulated microgravity, the ChE activity was affected. If compared to the control group (Figure 1A), the enzyme activity was increased in the cytoplasmic and perinuclear regions (control $=13.1 \% \pm 20 \%$ of the total activity $-6 \mathrm{~h}=73.2 \% \pm 16 \%$ of the total activity; $\mathrm{P}<0.001)$, while it was decreased in association to the cell membrane (control $=86.9 \% \pm 18 \%$ of the total activity $6 \mathrm{~h}=26.8 \% \pm 17 \%$ of the total activity; $\mathrm{P}<0.001$ ) (Figure $1 \mathrm{~B}$ ). The increase or decrease in the ChE activity was more evident in those cells exposed to modeled microgravity for $24 \mathrm{~h}$ ( $24 \mathrm{~h}$ cytoplasmic and perinuclear activity $=83.9 \% \pm 19 \%$ of the total activity; $\mathrm{P}<0.001$ - $24 \mathrm{~h}$ cell membrane activity $=16.1 \% \pm 16 \%$ of the total activity; $\mathrm{P}<0.001$ ) (Figure 1C). Cells exposed for $48 \mathrm{~h}$ to microgravity (Figure 1D) showed an increase in the ChE activity associated to the cell membrane $(48 \mathrm{~h}=37.5 \% \pm 18 \%$ of the total activity; $\mathrm{P}<0.001)$.
Furthermore, the activity in the cytoplasm was still more evident than in the control group $(48 \mathrm{~h}=62.5 \% \pm 19 \%$ of the total activity; $\mathrm{P}<0.001)$.

After $72 \mathrm{~h}$ of exposure to microgravity (Figure 1E), the localization of the staining returned similar to the one of the control $(72 \mathrm{~h}$ cell membrane activity $=87.0 \% \pm 19 \% ; \quad \mathrm{P}>0.05 \quad-72 \mathrm{~h}$ cytoplasmic and perinuclear activity $=13.0 \% \pm 16 \% ; \mathrm{P}>0.05$ ).

Figure 2 shows the effect of Earth's gravity conditions $(1 \mathrm{~g})$ on cells that were previously exposed to simulated microgravity. Paramecium cells submitted for $24 \mathrm{~h}$ to modeled microgravity and then placed for another 24h under Earth's gravity (Figure 2B') did not show differences in the Karnovsky and Roots staining (24h cell membrane activity $=17 \% \pm 15 \% ; \mathrm{P}>0.05-24 \mathrm{~h}$ cytoplasmic and perinuclear activity $=83.0 \% \pm 18 \% ; \mathrm{P}>0.05)$, if compared to those cells that were only exposed to simulated microgravity for $24 \mathrm{~h}$ (Figure 2B) (24h cell membrane activity $=16.1 \% \pm 16 \%-24 \mathrm{~h}$ cytoplasmic and perinuclear activity $=83.9 \% \pm 19 \%$ ). In contrast with the control, the ChE activity was localized mainly in the cytoplasm and only slightly on the cell membrane. However, after $48 \mathrm{~h}$ under Earth's gravity conditions (Figure 2B"), the localization of the ChE activity progressively decreased in the cytoplasm $(14 \% \pm 13 \%$ of the total activity; $\mathrm{P}>0.05$ ), while increasing on the membrane $(85 \% \pm 21 \%$ of the total activity; $\mathrm{P}>0.05)$, becoming similar to the pattern showed by the control (Figure $2 \mathrm{~A}$ ) (control $=13.1 \% \pm 20 \%$ of the total activity $-86.9 \% \pm 18 \%$ of the total activity). Conversely, cells exposed for $48 \mathrm{~h}$ and $72 \mathrm{~h}$ to simulated microgravity and then restored to Earth's gravity for $24 \mathrm{~h}$, displayed the $\mathrm{ChE}$ activity at the perinuclear level, and a decrease in the membrane staining localization ( $48 \mathrm{~h}$ cell membrane activity $=27.0 \% \pm 15 \% ; 48 \mathrm{~h}$ cytoplasmic and perinuclear activity $=73.0 \% \pm 15 \%-72 \mathrm{~h}$ cell membrane activity $=67.0 \% \pm 19 \% ; 72 \mathrm{~h}$ cytoplasmic and perinuclear activity $=33.0 \% \pm 16 \%$ ).

However, after $48 \mathrm{~h}$ under Earth's gravity conditions, the localization of the ChE activity progressively decreased at the cytoplasmic level $(48 \mathrm{~h}=16 \% \pm 22 \%$ of the total activity; $72 \mathrm{~h}=14 \% \pm 16 \%$ of the total activity), while it increased on the
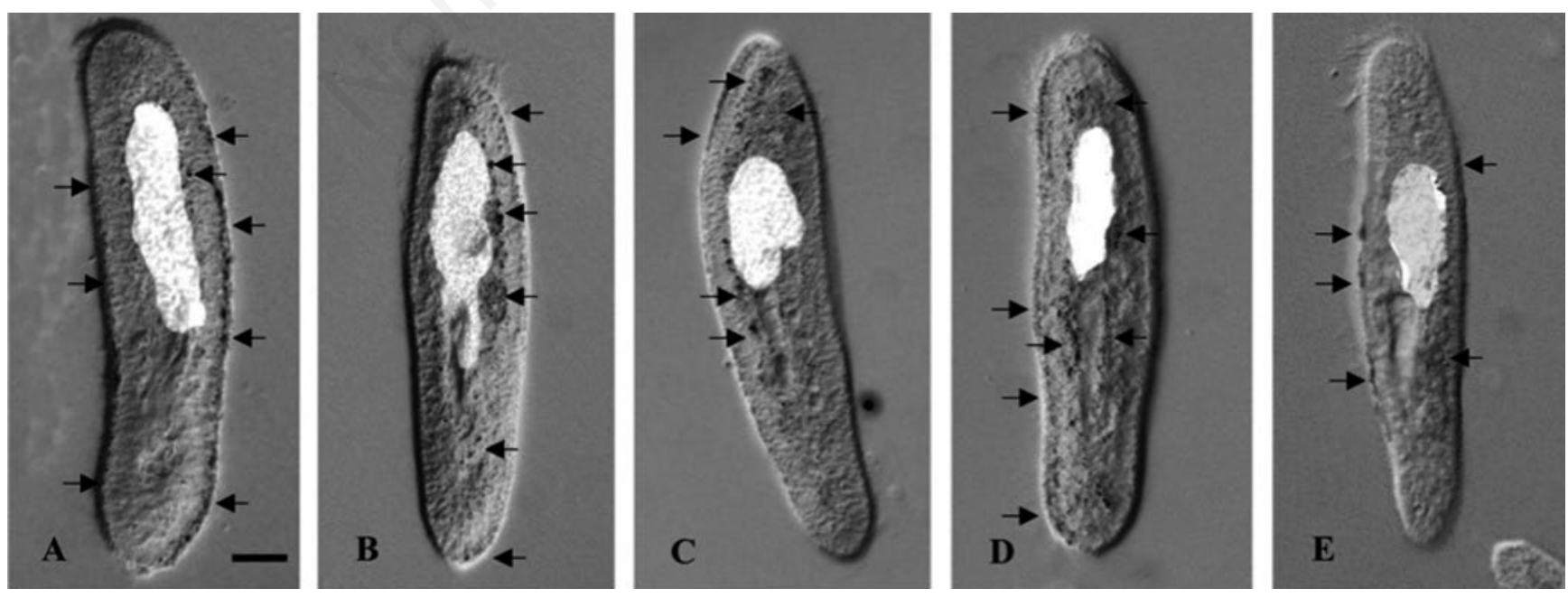

Figure 1. Cytochemical detection (Karnovsky and Roots method, 1964) of the cholinesterase activity in cells of Paramecium primaurelia exposed to simulated microgravity for $6 \mathrm{~h}(\mathrm{~B}), 24 \mathrm{~h}(\mathrm{C}), 48 \mathrm{~h}(\mathrm{D})$ and $72 \mathrm{~h}(\mathrm{E})$. The reaction was carried out using acetyl- $\beta$-methyl thiocholine iodide as substrate. The enzyme reaction product appears as a black precipitate (arrows). The white fluorescence evidences the macronucleus. $A=$ control. Bar= $15 \mu \mathrm{m}$. 
membrane $(48 \mathrm{~h}=84 \% \pm 18 \%$ of the total activity; $72 \mathrm{~h}=86 \% \pm 12 \%$ of the total activity) (Figure 2C", 2D"), becoming similar to the staining of the control (Figure 2A).

\section{Effects of simulated microgravity on the amount of the cholinesterase activity in Paramecium primaurelia}

Figure 3 shows differences in the amount of ChE activity in $P$. primaurelia exposed to simulated microgravity for $6 \mathrm{~h}(\mathrm{~B}), 24 \mathrm{~h}(\mathrm{C})$,
$48 \mathrm{~h}$ (D), $72 \mathrm{~h}$ (E). After $6 \mathrm{~h}$ and $24 \mathrm{~h}$ there was not a significant increase in the ChE activity respect to the control (A) $(\mathrm{P}>0.05)$. However, the activity increased after $48 \mathrm{~h}$ of exposure to simulated microgravity, becoming significantly $(\mathrm{P}<0.001)$ higher than both the control and the samples exposed for $6 \mathrm{~h}$ and $24 \mathrm{~h}$. In contrast, after $72 \mathrm{~h}$ of exposure to modeled microgravity, the ChE activity was not significantly different than that of the control $(\mathrm{P}>0.05)$.

Figure 4 shows the effect of restored Earth's gravity on $P$.
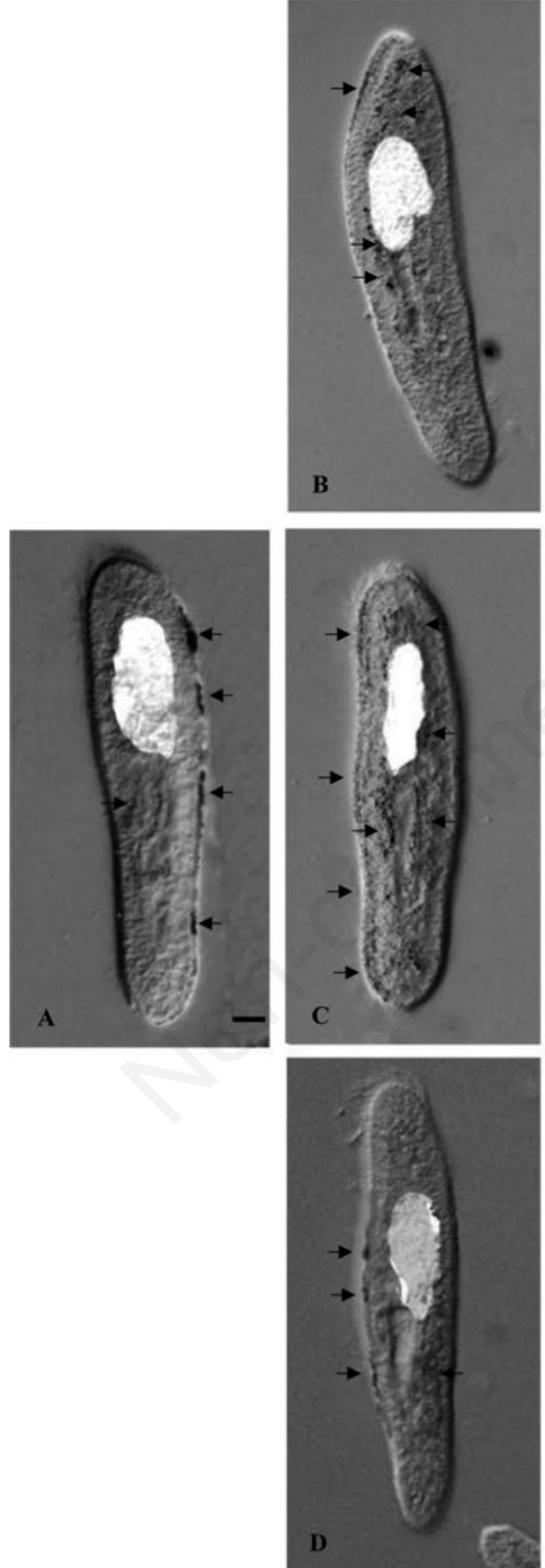
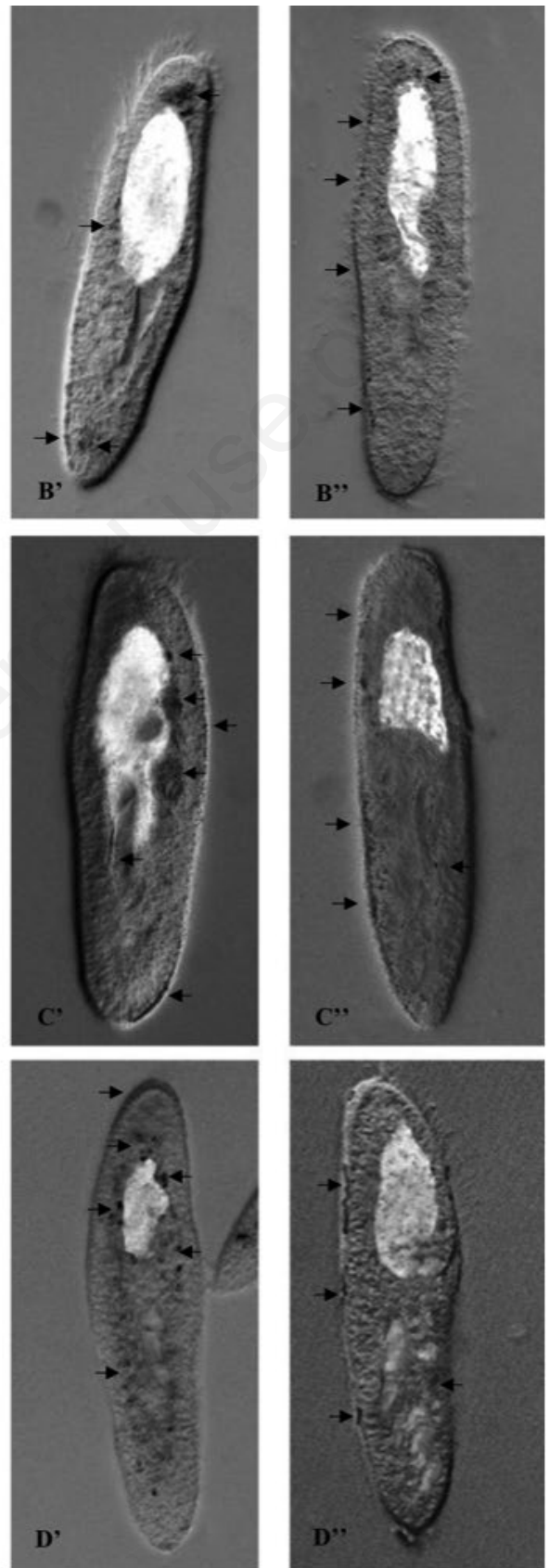

Figure 2. Cytochemical detection (Karnovsky and Roots method, 1964) of the cholinesterase activity in cells of Paramecium primaurelia. The reaction was carried out using acetyl- $\beta$-methyl thiocholine iodide as substrate. Cells were exposed to simulated microgravity for $24 \mathrm{~h}(\mathrm{~B}), 48 \mathrm{~h}(\mathrm{C})$ and $72 \mathrm{~h}(\mathrm{D})$. After exposure to microgravity, the cells were restored to Earth's gravity for $24 \mathrm{~h}\left(\mathrm{~B}^{\prime}, \mathrm{C}^{\prime}, \mathrm{D}^{\prime}\right)$ and $48 \mathrm{~h}$ (B”, C', D”). The enzyme reaction product appears as a black precipitate (arrows). The white fluorescence evidences the macronucleus. $A=$ control. Bar $=15 \mu \mathrm{m}$. 
primaurelia cells previously exposed from $24 \mathrm{~h}$ up to $72 \mathrm{~h}$ to simulated microgravity. Cells exposed for $24 \mathrm{~h}$ to simulated microgravity and then replaced under terrestrial gravity for $24 \mathrm{~h}$ (Figure B) or $48 \mathrm{~h}$ (Figure 4B"), maintained the same level of the enzyme activity, showing a value similar to that of the control (Figure 4A) $(\mathrm{P}>0.05)$. Cells exposed for $48 \mathrm{~h}$ to simulated microgravity and then kept under Earth's gravity, mantained the same high level $(\mathrm{P}<0.001)$ of $\mathrm{ChE}$ activity during the first $24 \mathrm{~h}\left(\mathrm{C}^{\prime}\right)$, then it decreased and after $48 \mathrm{~h}$ at $1 \mathrm{~g}(\mathrm{C}$ ") the enzyme activity returned to the control value $(\mathrm{P}>0.001)$. Finally, Paramecium cells exposed for $72 \mathrm{~h}$ to microgravity and submitted to Earth gravity for another $24 \mathrm{~h}$ (D'), increased the ChE activity $(\mathrm{P}<0.05)$. The enzyme activity displayed a decrease after $48 \mathrm{~h}$ at $1 \mathrm{~g}$ (D"), showing a value similar to the one of the control $(\mathrm{P}>0.05)$.

\section{Discussion}

The relationship among living organisms occurs via what is known as irritation events. ${ }^{9}$ The mechanism of irritability appears to have a common base in the form of chemical signals. ${ }^{9}$ Compounds like acetylcholine have been found not only in humans and animals, but also in living organisms which lack a nervous system, ${ }^{9}$ including Paramecium. ${ }^{8}$ In particular, in P. primaurelia has been described a cholinergic-like system and its role in the cell-cell interaction during the developmental cycle has been proven. ${ }^{8,27}$ This function, similar to the one observed in nerve cells, shows that the role of cholinergic system evolved from bacterial chemotaxis (nutrition, growth, attraction, defense, repellency) to cell-cell interactions among organisms of the same species, as described in protozoa, animals and humans. ${ }^{9}$

In our study, the exposure of $P$. primaurelia to simulated microgravity influenced the localization and the amount of ChE, compared to cells grown under Earth's gravity conditions $(1 \mathrm{~g})$. In particular, after $6 \mathrm{~h}$ and $24 \mathrm{~h}$ of simulated microgravity, the ChE was mainly localized in the perinuclear and cytoplasmic regions rather than on the cellular membrane. It is well known that in $P$. primaurelia, as well as in nerve cells, the $\mathrm{ChE}$ is synthesized in the perinuclear compartment and then the enzyme is transferred to the cell membrane, where it plays an important role in the modulation of cellular interaction. Therefore, a change in its location induces alterations in the cell-cell communications. In our previous work on NTera2 cells, pluripotent cells that are able to differentiate into cholinergic cells, we showed that the process of differentiation into neuronal phenotype is altered by environmental perturbations, as a consequence of an unsuccessful transfer from the perinuclear compartment, typical of undifferentiated cells, to the cell membrane, typical of excitable cells. ${ }^{15}$

In an attempt to restore the cellular homeostasis and the proper cellular communication, $P$. primaurelia cells showed an increase in the production of $\mathrm{ChE}$, which seemed to reach its maximum after 48 hours of exposure to simulated microgravity. This finding is in agreement with a study on the protozoan Dictyostelium discoideum, which showed an increase in the amount of $\mathrm{ChE}$ after the exposure to an electromagnetic field of low intensity and frequency. ${ }^{28}$ Paramecium cells, as observed in Dictyostelium cells, ${ }^{28}$ increased the $\mathrm{ChE}$ in the attempt to restore the proper homeostasis, through a

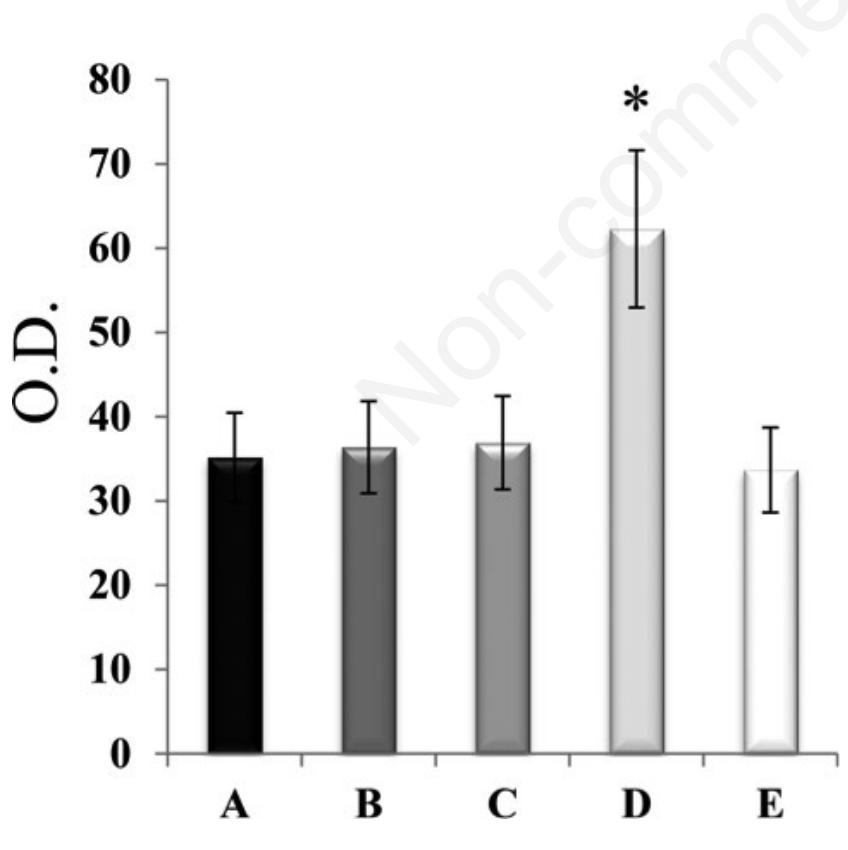

Figure 3. Image analysis of the electrophoretic pattern of the cholinesterase (ChE) activity detected with the Karnovsky and Roots method (1964). The figure shows the effect of simulated microgravity on the amount of the $\mathrm{ChE}$ activity in Paramecium primaurelia. Cells were placed in the clinostat and exposed to simulated microgravity for $6 \mathrm{~h}(\mathrm{~B}), 24 \mathrm{~h}(\mathrm{C}), 48 \mathrm{~h}(\mathrm{D})$ or $72 \mathrm{~h}(\mathrm{E})$. $\mathrm{A}=$ control. The values that are statistically different from the control are marked with a star symbol (*). O.D., Optical density.

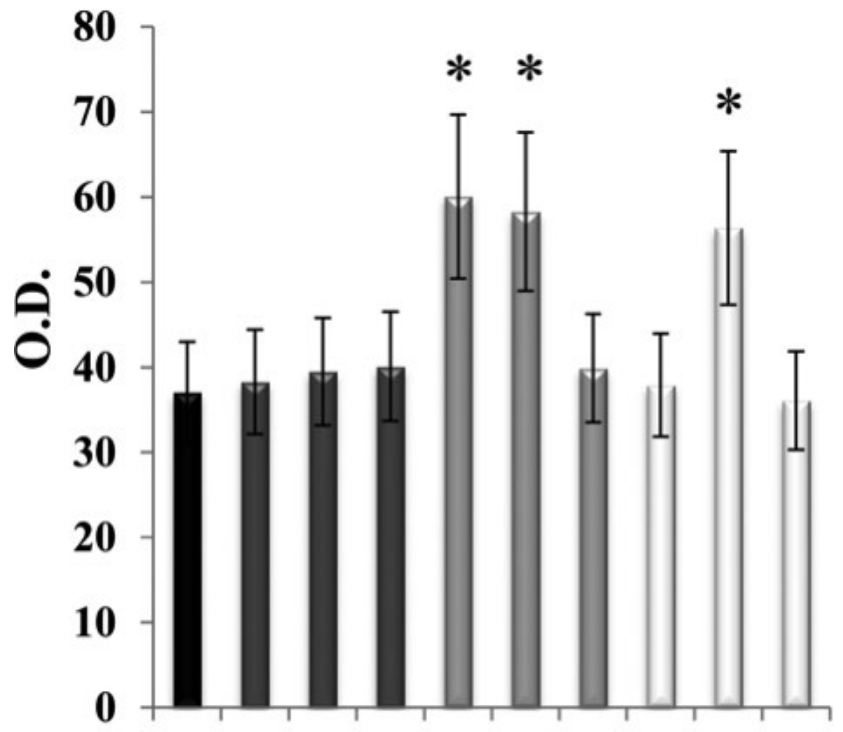

A B B' B" C C' C" D D' D"

Figure 4. Image analysis of the electrophoretic pattern of the cholinesterase (ChE) activity detected with the Karnovsky and Roots method (1964). The figure shows the effects of Earth's gravity (1g) on the amount of the ChE activity in Paramecium primaurelia previously exposed to simulated microgravity. Cells were placed in the clinostat for $24 \mathrm{~h} \mathrm{(B),} 48 \mathrm{~h}(\mathrm{C})$ or $72 \mathrm{~h}(\mathrm{D})$ and then recovered to Earth's gravity for 24 h (B', C', D') or 48 h (B', C', D") $A=$ control. The values that are statistically different from the control are marked with a star symbol $\left({ }^{*}\right)$. O.D., Optical density. 
process of hormesis similar to the one shown by the cells of vertebrates.

Paramecium cells seemed to adapt themselves to the new conditions of simulated microgravity after $72 \mathrm{~h}$, when the ChE activity returned to the control value. After $24 \mathrm{~h}$ and $48 \mathrm{~h}$, there was an initial alteration in the pattern of ChE. However, the effect of microgravity seemed to be reversible, since cells restored to Earth's gravity showed, after $48 \mathrm{~h}$, a localization and amount of cholinesterase similar to the ones of the control. These results suggest that Paramecium cells are more able to adapt themselves to Earth's gravity after exposure to microgravity, rather than the opposite situation. However, this hypothesis needs more insights to be confirmed.

Li et al. ${ }^{29}$ showed that modeled microgravity induced disorganization of cytoskeleton filaments (microfilaments and microtubules) as well as Janmaleki et al. ${ }^{30}$ described that simulated microgravity was able to disorganize actin filaments, microtubules and to reduce main cytoskeleton components. Corydon et al. ${ }^{31}$ proved by life-cell-imaging that significant alterations of the cytoskeleton occurred during microgravity exposure.

However, studies on cell cultures exposed to microgravity showed that the cytoskeleton, after an initial alteration, was able to adapt to the new conditions of gravity. ${ }^{32,33}$ In order to move from the perinuclear level to the cell membrane, ChE needs cytoskeletal filaments working properly, so we can assume that also in $P$. primaurelia, the different pattern of the ChE activity presence is correlated to initial alteration of cytoskeletal structure followed by a recovery in $48 \mathrm{~h}$ or $72 \mathrm{~h}$.

\section{Conclusions}

Our results show that $P$. primaurelia cells are able to cope with gravity variation. Alteration in the localization and amount of $\mathrm{ChE}$ for $24 \mathrm{~h}$ and $48 \mathrm{~h}$ have not irreversible effects on the cells of $P$. primaurelia during the phase of asexual reproduction. However, this result raises questions about the possible effects during the phase of sexual reproduction (conjugation). The conjugation is a delicate and peculiar phase of the reproductive cycle of Paramecium and it requires accurate and timely cellular interactions in which the $\mathrm{ChE}$ plays an important role. ${ }^{27}$ The same question could be raised for neuronal development in humans, since this process involves $\mathrm{ChE}$ and requires specific steps that, if altered, would lead to redundancy and disorders in the formation of synapses. ${ }^{15}$

\section{References}

1. Häder DP, Hemmersbach R, Lebert M. Gravity and the behavior of unicellular organisms. Cambridge: Cambridge University Press; 2005.

2. Lackner JR, DiZio P. Human orientation and movement control in weightless and artificial gravity environments. Exp Brain Res 2000; 130:2-26.

3. Baroni G, Ferrigno G, Rabuffetti M, et al. Long-term adaptation of postural control in microgravity. Exp Brain Res 1999;128:410-6.

4. Ross MD. A spaceflight study of synaptic plasticity in adult rat vestibular maculas. Acta Otolaryngol 1994;516:1-14.

5. Uva BM, Masini MA, Sturla M, et al. Simulated microgravity induces alteration in the central nervous system. J Gravit Physiol 2001;8:P93-5.
6. Amaroli A, Chessa MG. Detection and characterisation of NAD(P)H-diaphorase activity in Dictyostelium discoideum cells (Protozoa). Eur J Histochem 2012;56:4:e47.

7. Amaroli A, Trielli F, Sifredi F, et al. Nitric oxide production is inhibited by xenobiotic compounds in the protozoan Paramecium primaurelia. Ecol Indic 2010;10:212-6.

8. Delmonte Corrado MU, Politi H, Ognibene M, et al. Synthesis of the signal molecule acetylcholine during the developmental cycle of Paramecium primaurelia (Protista, Ciliophora) and its possible function in conjugation. J Exp Biol 2001;204:1901-7.

9. Roshchina VV. Evolutionary considerations of neurotransmitters in microbial, plant, and animal cells. In: Lyte M, ed. Microbial Endocrinology. New York, NY: Springer; 2010. pp 17-52.

10. Dessen P, Zagulski M, Gromadka R, et al. Paramecium genome survey: a pilot project. Trends Genet 2001;17:306-8.

11. Amaroli A, Benedicenti A, Ferrando S, et al. Photobiomodulation by infrared diode laser: effects on intracellular calcium concentration and nitric oxide production of Paramecium. Photochem Photobiol 2016;92:854-62.

12. Amaroli A, Ravera S, Parker S, et al. Effect of $808 \mathrm{~nm}$ diode laser on swimming behavior, food vacuole formation and endogenous ATP production of Paramecium primaurelia (Protozoa). Photochem Photobiol 2015;91:1150-5.

13. Amaroli A, Ravera S, Parker S, et al. 808-nm laser therapy with a flat-top handpiece photobiomodulates mitochondria activities of Paramecium primaurelia (Protozoa). Lasers Med Sci 2016;31:741-7.

14. Amaroli A, Ravera S, Parker S, et al. Paramecium primaurelia (Protozoa) a non-sentient model to test laser light irradiation: a study on the effect of a $808 \mathrm{~nm}$ infrared laser diode on cellular respiration. ATLA - Alt Lab Anim 2015;43:155-62.

15. Amaroli A, Aluigi MG, Falugi C, Chessa MG. Effects of the neurotoxic thionophosphate pesticide chlorpyrifos on differentiating alternative models. Chemosphere 2013;90: 2115-22.

16. Amaroli A, Parker S, Dorigo G, et al. Paramecium: a promising non-animal bioassay to study the effect of $808 \mathrm{~nm}$ infrared diode laser photobiomodulation. Photomed. Laser Surg 2015;33:35-40.

17. Amaroli A, Benedicenti A, Ravera S, et al. Short-pulse neodymium:yttrium-aluminium garnet (Nd:YAG 1064nm) laser irradiation photobiomodulates mitochondria activity and cellular multiplication of Paramecium primaurelia (Protozoa). Eur J Protistol 2017;61:294-304.

18. Planel H, Richoilley G, Tixador R, et al. Space flight effects on Paramecium tetraurelia flown aboard Salyut 6 in the Cytos 1 and Cytos M experiment. Adv Space Res 1981;1:95.

19. Ayed M, Pironneau O, Planel H, et al. Theoretical and experimental investigations on the fast rotating clinostat. Micrograv Sci Technol 1992;5:98-102.

20. Hemmersbach-Krause R, Briegleb W, Vogel K, Hader DP. Swimming velocity of Paramecium under the conditions of weightlessness. Acta Protozool 1993;32:229-36.

21. Sawai S, Mogami Y, Baba SA. Cell proliferation of Paramecium tetraurelia on a slow rotating clinostat. Adv Space Res 2007;39:1166-70.

22. Hemmersbach R, Braucker R. Gravity-related behavior in ciliates and flagellates. In: Cogoli A, ed. Cell biology and biotechnology in space. Amsterdam, NL: Elsevier; 2002. pp 59-75.

23. Russomano T, Cardoso R, Falcao F, et al. Development and validation of a $3 \mathrm{~d}$ clinostat for the study of cells during microgravity simulation. Conf Proc IEEE Eng Med Biol Soc 2005;1:564-6. 
24. Karnovsky MJ, Roots LA. Direct coloring thiocholine method for cholinesterase. J Histochem Cytochem 1964;12:219-21.

25. Falugi C, Amaroli A, Evangelisti V, et al. Cholinesterase activity and effects of its inhibition by neurotoxic drugs in Dictyostelium discoideum. Chemosphere 2002;48:407-14.

26. Amaroli A. The effects of temperature variation on the sensitivity to pesticides: A study on the slime mould Dictyostelium discoideum (Protozoa). Microb Ecol 2015;70:244-54.

27. Delmonte Corrado MU, Politi H, Trielli F, et al. Evidence for the presence of a mammalian-like cholinesterase in Paramecium primaurelia (Protista, Ciliophora) developmental cycle. J Exp Zool 1999;283:102-5.

28. Amaroli A, Trielli F, Bianco B, et al. Effects of time-variant extremely-low-frequency (ELF) electromagnetic fields (EMF) on cholinesterase activity in Dictyostelium discoideum (Protista). Chem Biol Interact 2005;157-8:355-6.
29. Li J, Zhang S, Chen J, et al. Modeled microgravity causes changes in the cytoskeleton and focal adhesions, and decreases in migration in malignant human MCF-7 cells. Protoplasma 2009;238:23-33.

30. Janmaleki M, Pachenari M, Seyedpour SM, et al. Impact of simulated microgravity on cytoskeleton and viscoelastic properties of endothelial cell. Sci Rep 2016;6:32418.

31. Corydon TJ, Kopp S, Wehland M, et al. Alterations of the cytoskeleton in human cells in space proved by life-cell imaging. Sci Rep 2016;6:20043.

32. Buravkova LB, Romanov YA. The role of cytoskeleton in cell changes under condition of simulated microgravity. Acta Astronaut 2001;48:647-50.

33. Uva B, Masini MA, Sturla M, et al. Clinorotation-induced weightlessness influences the cytoskeleton of glial cells in culture. Brain Res 2002;934:132-9. 